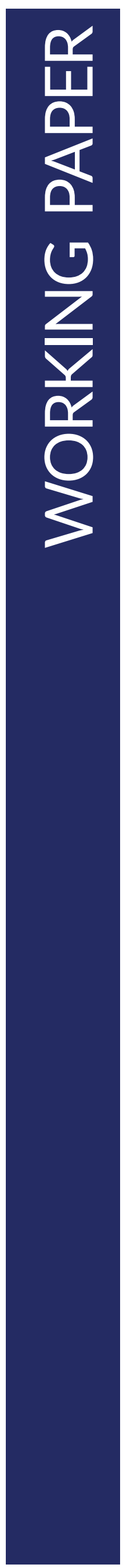

\title{
Celebrating the impact of the Raising Learning Outcomes in Education Systems Programme
}

A focus on how to achieve impact is often a key aspect of policy-relevant social science research in international development settings. Done well, planning for impact from the outset of the project is based upon informed thinking and reflection on how research teams can draw upon and strengthen their networks and relationships to develop, share, and promote their research findings. However, it may be several years before the relevance of some research is fully recognised and implemented, or for changes to take place in social and economic systems.

This paper provides a snapshot of the impact achieved by the UK's Economic and Social Research Council (ESRC) and the Foreign, Commonwealth \& Development Office (FCDO) funded Raising Learning Outcomes in Education Systems Research Programme (RLO). It provides a reflection on the different types of impact that research projects have achieved to inform discussion and learning around impact pathways for both researcher and funders.

\section{THE IMPACT INITIATIVE PROGRAMME}

The Impact Initiative programme, funded by the UK's Economic and Social Research Council (ESRC) and the Foreign, Commonwealth $\&$ Development Office (FCDO), formerly the Department for International Development (DFID), aims to increase the uptake and impact of research from two research programmes: the Joint Fund for Poverty Alleviation Research and the Raising Learning Outcomes in Education Systems Research Programme (RLO), both jointly funded by ESRC-FCDO. The Impact Initiative achieves this through a process of identifying synergies between the two programmes and amongst their project portfolios, and supporting them collectively and individually to exploit influencing and engagement opportunities the lessons and recommendations from this approach to brokering evidence are provided in
'Maximising the Impact of Global Development Research: A New Approach to Knowledge Brokering' (Georgalakis and Rose 2021). As well as facilitating knowledge exchange and policy engagement on behalf of the two programmes, the Impact Initiative develops programme-level research communication outputs in order to ensure each programme's research is effectively communicated and shared. This involves working across the wide variety of research approaches, thematic areas, and geographic coverage of the portfolio, to pinpoint how individual projects complement each other and together offer a coherent message to support policy and practice (for example, through our Research for Policy and Practice Papers which cover education-related themes including disability, gender, teaching and accountability).

\section{THE RAISING LEARNING OUTCOMES PROGRAMME}

Since 2015, the ESRC-FCDO Raising Learning Outcomes in Education Systems Research Programme (RLO) has filled critical evidence gaps on questions of how education systems can work better to overcome the global learning crisis and raise learning outcomes at scale in developing countries. Understanding how to raise learning outcomes at scale is a global priority, highlighted by the education Sustainable Development Goal (SDG 4). It is estimated that over 90 per cent of primary-age children in low-income countries cannot read nor do basic maths by the end of 
primary school (UNESCO Institute for Statistics 2017). The RLO programme's 30 world-class research grants have focused on three core themes: effective teaching, challenging contexts, and accountability mechanisms. This has produced rigorous and policy-relevant research on how to raise learning outcomes globally, which have provided policymakers and practitioners with concrete ideas on how to improve learning and an understanding of how these will translate to their specific contexts and institutions.

This paper provides an overview of the different types of impact delivered in six years of the RLO portfolio. Given the richness of the portfolio, it is not possible to capture all the examples of impact. Rather, the paper aims to highlight the diversity of forms of impact. The Impact Initiative has analysed the outcomes reported by 30 RLO projects, to identify the types of outcomes that have been achieved, gather researcher reflections on their pathways, and explore the lessons that have been learned with regards to increasing the uptake and impact of research. Our approach took the wheel of impact (see Figure 1) as the starting point. This builds upon the ESRC definitions of impact (UKRI ESRC 2021) - instrumental, conceptual, and capacity building - and has been expanded to include networks and activity which emphasises the relational dimensions of impact (Georgalakis et al. 2017; Georgalakis and Rose 2019). The aim of this paper is to unpack these broad categories in order to identify the different outcomes within each and reflect on the patterns and pathways to impact across the portfolio to provide new insights into the processes through which research supports outcomes and impact with respect to raising learning outcomes.

\section{METHOD FOR MAPPING META-IMPACT PATHWAYS}

In order to understand and establish the impact that had been achieved by the RLO programme, the Impact Initiative conducted a rapid review of RLO documentation from three sources: Gateway to Research (UK Research and Innovation's portal for publicly funded research and innovation); ESRC reports (with a focus on the Pathways to Impact sections); and content developed in collaboration with the Impact Initiative to highlight the impact of projects (such as Impact Stories and Research for Policy and Practice papers). This report is based upon the review of these data to conduct a meta-mapping of outcomes across the portfolio and subsequent webinar discussions of this data with RLO grant holders. It is not an evaluation of the outcomes of the RLO programme.

This information was used to conduct a meta-impact pathway mapping exercise, applying an Outcome Harvesting approach to identify, formulate, verify, analyse, and interpret the different types of outcomes reported across the research portfolio (Wilson-Grau 2018). This approach builds upon previous meta-impact pathway analysis by the Impact Initiative (Clark and Goodier 2019). Using the wheel of impact as the starting point the review mapped and categorised the different types of outcomes reported by projects, identifying the subcategories presented in Figure 2. The connections between individual grants and the outcome areas identified were visualised using Kumu, a systems mapping platform to create a 'meta-impact pathway' as seen in Figure 3. This map highlights the wealth of experience and diversity of outcomes, ranging from stakeholder capacity building, network-strengthening among advocates, building new conceptual understanding and direct policy influence that has accumulated across the RLO portfolio.

\section{Figure 1 The Impact Initiative's Wheel of Impact}

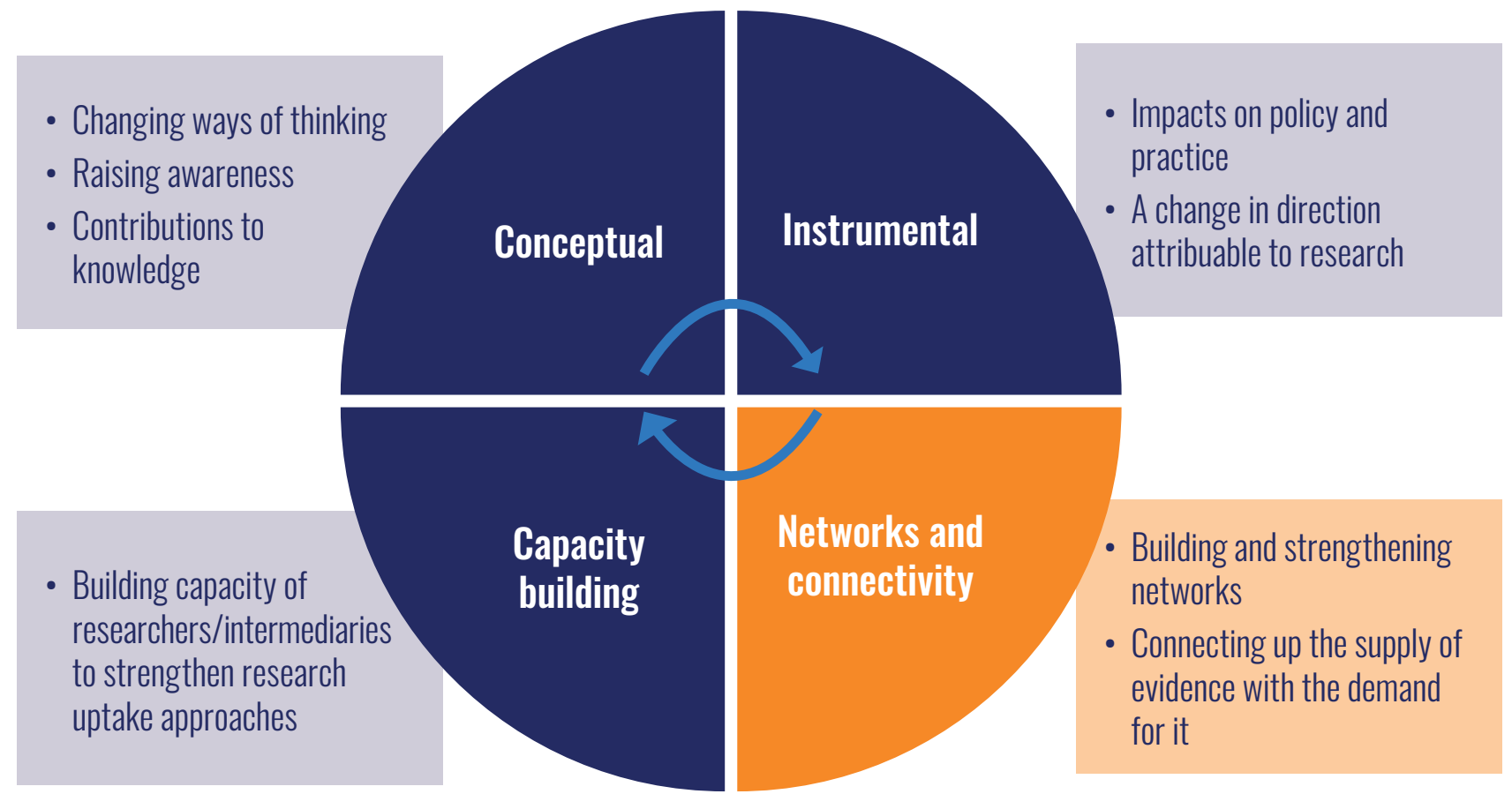




\section{Capacity building}

\section{- Strengthened} capacities of either researchers, partners, or participants in impact-generating activities

- Capacity of beneficiary groups to participate or engage with research

- New or improved approaches or strategies to support research uptake
Networks and Connectivity

- Stakeholder platforms or spaces that bring different voices together

- Partnerships with civil society/ practitioners/policy or other relevant groups

- Opportune engagements with diverse groups to inform the research process or expand the reach of the evidence

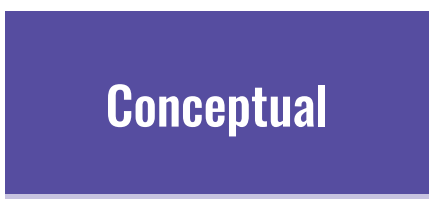

- Approaches that have built awareness of an issue or put it on an agenda

- Evidence of a shift in the dialogue and discourse around a particular issue

\section{Instrumental}

- Evidence of having influenced a policy document or statement

- Shifts in practice - new teaching approaches, including to promote inclusion

Source: Impact Initiative

The results of this mapping exercise were presented to RLO grant holders at an online webinar to discuss and reflect on their collective experience of why they chose specific strategies and stakeholder groups, whether their pathways to impact progressed as planned, and whether and how adjustments were made along the way.

\section{EXAMPLES OF IMPACT IN EDUCATION-DEVELOPMENT RESEARCH}

There is not a single 'impact pathway' or any magic formula to research impact. Researchers use multiple strategies and engage with a range of stakeholders across different spaces to build capacities, establish and strengthen relationships, to shift perceptions and influence discourse and policy conversations. These multiple strategies deliver a broad range of outcomes and highlight the dynamic interaction between research and engagement processes with the capacity, relational and conceptual outcomes that create the foundations for achieving the instrumental outcomes of influencing policy and practice and can also have significant and sustainable consequences in raising learning outcomes. From a pathways' perspective, the line between research and engagement processes, and the outcomes they generate, can become quite blurred. This highlights the value of taking a broad view of impact to include each of the dimensions of the wheel of impact. And while a pathway suggests a linear view with a starting point, destination and clear signposts along the way, the reality of research impact is iterative and uncertain, requiring a balance of proactive planning and reactive response to evolving contexts and emerging opportunities.

Our mapping provides a clear overview of how the RLO programme has achieved outcomes across each of the four broad dimensions of impact, and the interconnectedness of these at the project level. This paper will discuss each of the outcomes, highlighting indicative and illustrative examples from across the portfolio. Many grants have outcome examples from each of the dimensions of the wheel of impact, and so are mentioned more than once. Inevitably, there is also overlap within and between the different forms of impact such that examples could be relevant in different sections. For simplicity, we identify examples to illustrate specific areas, while recognising they could be cross-cutting. 


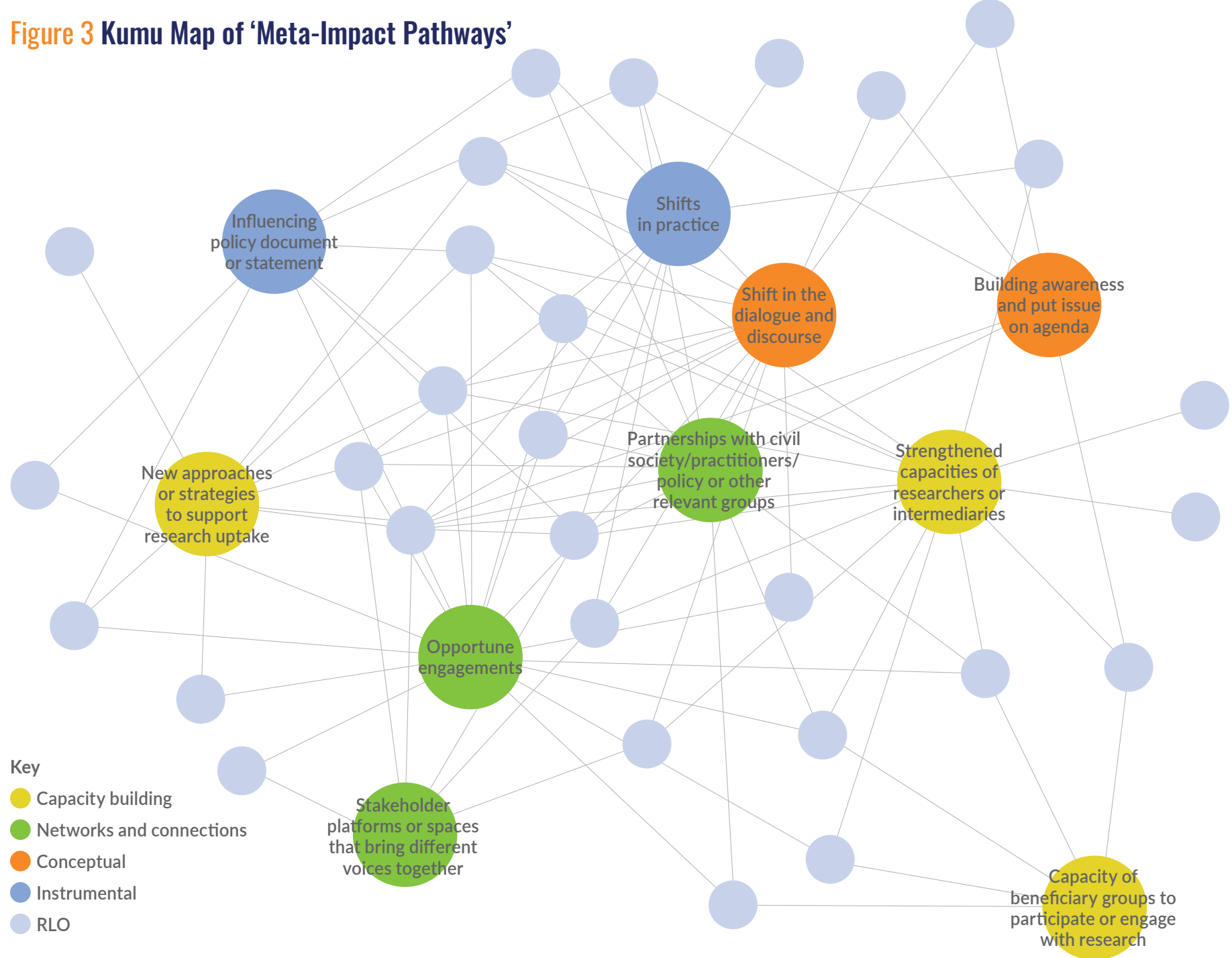

Source: Impact Initiative

\section{CAPACITY BUILDING}

Developing the skills of researchers as well as key stakeholders and audiences to engage with and shape an issue is often crucial to success. The analysis of the RLO portfolio showed that many projects reported how they had strengthened the capacities of practitioners and/or intermediaries to engage in research and engagement activities. This facilitated the building of mutual understanding and expanded knowledge on key issues and challenges related to raising learning outcomes.

\section{Strengthened capacities of researchers, partners, and intermediaries to engage in impact-generating activities}

Some projects worked in collaboration with government and other stakeholders to enhance skills in understanding and use of data for policy and planning. For example, by gathering large-scale data in Pakistan, ${ }^{1}$ researchers from the University of Cambridge, UK and the Institute of Development and Economic Alternatives (IDEAS), Pakistan were able to gain a fuller picture of the prevalence of disability in the country. Following the successful use of questions developed by the Washington Group for Disability Statistics (together with data on children's enrolment and learning patterns as well as information collected from households on other characteristics, such as poverty and gender), the Punjab Special Education Department was provided with training on how to use the Washington Group child functioning survey tools. This meant that data to identify children with disabilities were included in national surveys, resulting in more effective planning. Edward Davis, former DFID Pakistan Education Policy Team Leader, said: 'The research has been influential in training Punjab Special Education Departments on how to use the Washington Group child functioning survey tools'.

Capacity building also included practitioners developing presentation and writing skills, with multiple examples of publishing papers and supporting participation at international events and conferences. For many Southern partners, this was their first international experience. For example, Indian partners from a project on peer to peer deaf multiliteracies ${ }^{2}$

${ }^{1}$ Learning outcomes and teacher effectiveness for children facing multiple disadvantages, including those with disabilities: India and Pakistan (also known as 'Teaching Effectively All Children (TEACh) in India and Pakistan') - ES/M005445/1

Peer to peer deaf multiliteracies: research into a sustainable approach to education of deaf children and young adults in the Global South - ES/P008623/1 
led by the International Institute for Sign Languages and Deaf Studies (iSLanDS) at the University of Central Lancashire, presented their work at the SIGN9 international conference of sign language users in Warsaw, Poland. Two Ugandan and two Indian deaf members of this project wrote academic chapters for a book for the first time (Zeshan and Webster 2020). Twelve deaf participants from India, Uganda and Nepal were supported to develop pedagogical skills in an international training for deaf sign language users to act as professionals in language and literacy in deaf education. The involvement of deaf researchers in the work led by this Institute enabled several team members to access the next phase of their university education and continue on to further careers.

\section{Capacity of beneficiary groups to participate or engage with research}

Ensuring active engagement and participation of relevant groups in the research process is a key strategy to increase understanding of the challenges of the local context and increase the chances that target groups and communities are aware of emerging evidence and able to act upon and apply recommendations in practice. Designing projects to create spaces for mutual learning and contextualising emerging findings has been essential for many RLO grant holders.

Within the RLO portfolio this has involved working directly with teachers, parents, and community groups. For example, in a project on strengthening schools accountability mechanisms ${ }^{3}$ led by the University of Washington in St. Louis together with local partners the Swedish Committee for Afghanistan and the National Rural Support Programme in Pakistan, hundreds of teachers and community members from 90 schools in both countries were trained to better understand their school system and decide how to improve learning outcomes for all children.

In another example, in South Africa ${ }^{4}$ higher education students from three universities participated in a mixed-method study that explored the contextual factors - families, schools, university educational and social arrangements, and workreadiness activities - that enable and inhibit higher education pathways for these students. In particular, it investigated what learning outcomes are valued by students themselves and by other stakeholders. By understanding the student experiences and bringing them together for a training event, they were able to improve the quality of higher education training and increase their capacity to engage with research.

\section{New or improved approaches or strategies to support research uptake}

There is an established consensus that simply publishing research is insufficient to bring about research uptake and use. Effective communication and engagement strategies are needed to ensure that the lessons learnt from research projects are shared with a wider audience and increasingly researchers are employing a variety of innovative tools, concepts and methodologies in research uptake, policy and practice.

New approaches to support research uptake were demonstrated by a project in Uganda, ${ }^{5}$ where children whose first language is not the language of instruction in school are more likely to drop out or fail in early grades. The researchers from the Universities of Illinois and their Ugandan partners Mango Tree Educational Enterprises and the Ichuli Institute, Kampala, demonstrated that engaging indigenous writers, artists, designers, and technical experts, as well as teachers, to co-develop education materials in local languages led to large learning gains in rural, underresourced and overcrowded classrooms. This visual and interactive approach enabled the project to discuss findings with low-literacy populations, as well as engage civil society and government stakeholders in discussions around policy and impact.

Media and social media engagement are also useful strategies to disseminate research findings to support uptake and increase engagement around an issue with a number of different examples across the portfolio. The improving school governance and learning outcomes at scale project ${ }^{6}$ received national press coverage in India. A researcher from the multilingualism and multi-literacy to raise learning outcomes in India project, ${ }^{7}$ led by the University of Cambridge, was also interviewed on the research on a live telecast on the National Council of Educational Research and Training (NCERT), a training institute affiliated with the government that provides content on educational issues. A week-long training programme to build deaf instructors and graduates' skills in researching sign languages and deaf communities, ${ }^{8}$ delivered by the University of Central Lancashire in collaboration with the Rural Lifeline Trust in India, was supported by a series of Facebook posts and video summaries which generated 12,000 views.

\footnotetext{
Strengthening schools accountability mechanisms through participation: addressing education quality and equity in Afghanistan and Pakistan - ES/P005799/1

${ }_{4}$ Inclusive higher education learning outcomes for rural and township youth: developing a multi-dimensional capabilities-based higher education index - ES/N010094/1 The Literacy Laboratory Project (LLP) under the Northern Uganda Literacy Program - ES/M004996/1

Improving school governance and learning outcomes at scale: a randomized evaluation of the Madhya Pradesh School Quality Assessment program - ES/N010388/1

Multilingualism and multiliteracy: raising learning outcomes in challenging contexts in primary schools across India - ES/N010345/1

Literacy development with deaf communities using sign language, peer tuition, and learner-generated online content: sustainable educational innovation 
Strengthening the linkages between research and policy depends on the development of strong relationships between networks of stakeholders that will be able to directly effect change or influence those who are in a position to do so. The RLO portfolio has demonstrated a number of ways that these connections can be established and sustained.

\section{Stakeholder platforms or spaces that bring different voices together}

The analysis uncovered many examples of projects creating innovative spaces for discussion within national contexts, whether using virtual technologies or creative face to face activities. The techniques and tools used all aimed to facilitate diverse conversations and build a greater understanding on a range of issues.

For example, in a project on assessment for learning in Africa, ${ }^{9}$ led by University of Oxford with Aga Khan University and Tshwane University of Technology, messaging apps were used by teachers to share knowledge in real time in their own language, Kiswahili. In Malawi, a series of workshops ${ }^{10}$ were found to be the most effective way at establishing a dialogue between stakeholders at the national and international level. In this example, led by University of Birmingham in collaboration with the University of Malawi and Sightsavers International, a 'study group' comprised of representatives from a wide range of governmental, academic and non-governmental groups, including people with disabilities, were able to guide and oversee the implementation of the activities. Benefits of these workshops include building a shared knowledge of impact and the potential of the collective to establish a dialogue on disability and identifying communications tools and common themes for engaging with policy makers.

In another example, the Rights and Accountability in the Indian System of Education (RAISE) project, ${ }^{11}$ led by the University of Leeds in collaboration with the Vidya Bhawan Society and Centre for Social Equity and Inclusion, focused on learning outcomes for 'disadvantaged learners' in India by examining cross-cutting structural inequalities such as gender, location, caste, and class. The research team organised a national seminar to discuss inclusive education in collaboration with the National Council of Teacher Education and All India Association of Private Colleges. This event generated great awareness about inclusive education policies and laws in India, providing the space and the framing for an in-depth discussion on inclusive education by various policy makers, practitioners, and academic scholars.

In India, activities involving ten RLO projects contributed towards an evidence-based strategy of education policy reform in India. These activities were based on the successful pitch by the 'SCAFFOLD' (Stakeholder Convergence for Focus on Learner Disadvantage) team, as part of the Dragons' Den session at the annual RLO workshop in January 2019. The work built on previous activities to bring together India-focused grants in order to contribute towards an evidence-based strategy of education policy reform. Focused on raising learning outcomes for children facing different forms of disadvantage in diverse contexts, activities included a workshop and national dissemination event of the collaboratively-produced policy brief that was translated into Hindi, providing the opportunity for projects to engage with each other and decision makers at State level. Leadership by Southern-based research teams meant activities and outputs were contextually relevant and were able to elaborate on some issues presented by the draft national education policy. A large-scale networking event took place with a range of policy actors and researchers, creating the opportunity to discuss the national education policy. For one project, ${ }^{12}$ the event was the catalyst for discussions with members of the Haryana State Government for planning a workshop with teachers, as well as to present the evidence to government officials in the State.

\section{Partnerships with civil society/practitioners/policy or other relevant groups}

Many international development research projects seek to build relationships and networks and engage with a broad range of non-academic audiences to ensure research is grounded in their realities and responds to their challenges.

The analysis of the RLO portfolio found a number of examples of partnerships between academic and non-academic partners. In research led by University College London in collaboration with the University of KwaZulu-Natal (South Africa), University of East Anglia (UK) and the University of Malawi, focusing on accountability for gender equality in education in Malawi and South Africa, ${ }^{13}$ they engaged with key informants located in global women's rights networks and those who worked at the global level in multilateral, bilateral, NGO and large donor organisations. In their work to contribute to more inclusive gender framing for global education, the project convened a technical meeting on gender, which contributed to the work of UNESCO for the 2019 G7 meeting, which launched the Gender at the Centre Initiative. This established an ongoing relationship between the project team and UNESCO and UN Girls Education Initiative to work on gender responsive education sector planning and contribute to training materials for initiatives including Gender-Responsive Education Sector Planning and Gender at the Centre. 
In Bangladesh, a project ${ }^{14}$ led by Monash University, Australia, and supported by local partner the Global Development and Research Initiative Foundation, examines how to improve early years education in rural areas. Researchers are collaborating with international development organisation BRAC to evaluate a play-based early childhood development programme to help traumatised Rohingya child refugees. As a result of this collaboration, the team are also working with BRAC International in Tanzania and Uganda on pre-school interventions a using play-based curriculum.

\section{Opportune engagements with diverse groups that inform the research process or expand the reach of the evidence}

To ensure the evidence they are generating engages their target audiences, researchers need to interact with a range of different actors, processes and systems. The RLO portfolio includes several examples of project teams creating engagement opportunities with diverse groups, which contributed to expanding the reach of the evidence.

A research team based at Makerere University working on deaf education, as part of a project ${ }^{15}$ led by the University of Central Lancashire, engaged with education policymakers in Uganda, including the National Curriculum Development Centre (NCDC), to support work on curriculum and learning materials for sign language and deaf education. In Nepal, other non-academic stakeholders included the President of a local deaf association and three deaf schoolteachers.

Meanwhile, having influenced a United States Agency for International Development (USAID) White Paper on approaches to improving literacy instruction in Uganda, Mango Tree - the local partner of another research project in Uganda ${ }^{16}-$ developed multiple bids to implement the next phase of USAID's education programme. The project focused on children whose first language was not the language of instruction in school, as they recognised that they are more likely to drop out or fail in early grades. This research demonstrated that the provision of teacher support and educational resources produced in local languages could lead to large learning gains in rural, under-resourced and overcrowded classrooms.

\section{CONCEPTUAL IMPACT}

Conceptual impact reflects the ability to contribute to a greater understanding of an issue, influence the discourse on a specific subject or reframe debate (UKRI ESRC 2021). There is a myriad of examples of how the RLO portfolio has built new awareness or understanding of an issue or put it on the agenda. Strategies employed by RLO researchers to increase outreach and maximise research impact involve many potential uses and users of the evidence generated from across the RLO research portfolio. In the following examples it is possible to see the pathway from building relationships and networks to influencing stakeholders' narrative and understanding of an issue.

\section{Approaches that have built awareness of an issue or put it on the agenda}

A number of projects have worked with practitioners within countries to raise awareness of issues of relevance to teaching and learning, including with respect to putting innovations on to the national agenda. In a project led by University College London in collaboration with JET Education Service and Open University aimed at strengthening accountability, capacity and trust to improve learning outcomes in South Africa, ${ }^{17}$ an advisory board was established made up of practitioners who were working in and understood the context of school and district improvement. Central to the research was the need for better understanding to build trust between education providers and teaching unions. They imparted their knowledge and experience to benefit the project, but also raised awareness of the project with their existing networks. Another dimension was working closely with district officials to create a shared understanding of the high levels of inequality in their districts and how monitoring and accountability can be improved to enhance learning outcomes of schools serving deprived communities.

There has also been engagement with relevant national organisations to raise awareness. In India, the peer to peer deaf multiliteracies project, ${ }^{18}$ which looked at new ways of developing multiliteracies skills with deaf learners, worked closely with the National Institute of Open Schooling on adding Indian Sign Language as a school subject to their curriculum. Three project members, a UK academic and two Indian project staff, were invited to sit on the curriculum committee, and other researchers based at the Rural Lifeline Trust in Odisha worked on lesson production. This was regarded as major progress with respect to the visibility of Indian Sign Language, as this is the first initiative aiming to make it available nationally as a school subject.

There have also been examples of projects raising awareness of new approaches to teaching. A project focused on pedagogies for critical thinking ${ }^{19}$ led by University College London, UK, together with researchers from the University of Botswana, the University of Cape Coast in Ghana, and Strathmore University in Kenya, developed a series of seminars and presentations in each of the countries to raise awareness of how different teaching styles affect the development of critical thinking skills. Some of the events have reached undergraduate and graduate students, university practitioners, and the general public. The resulting reforms to teaching practices and processes to better prepare lecturers in the skill of fostering critical thinking are discussed in more detail below under instrumental impacts.

\footnotetext{
${ }^{14}$ Investing in our future: the early childhood intervention and parental involvement in Bangladesh - ES/N010221/1

${ }_{15}$ Peer to peer deaf multiliteracies: research into a sustainable approach to education of deaf children and young adults in the Global South - ES/P008623/1

${ }^{16}$ The Literacy Laboratory Project (LLP) under the Northern Uganda Literacy Program - ES/M004996/1

Accountability, capacity, and trust to improve learning outcomes in South Africa: a systems approach - ES/P005888/1

18 Peer to peer deaf multiliteracies: research into a sustainable approach to education of deaf children and young adults in the Global South - ES/P008623/1

${ }^{19}$ Pedagogies for critical thinking: innovation and outcomes in African higher education - ES/M005496/1
} 


\section{Evidence of a shift in the dialogue and discourse around a particular issue}

Several projects reported evidence of how research findings had influenced discourse on a particular issue under investigation. For example, research from projects in Uganda, ${ }^{20}$ Pakistan, ${ }^{21}$ and India ${ }^{22}$ have fed directly into government education strategy. In Uganda, the International Growth Centre (IGC) invited a researcher from the literacy laboratory

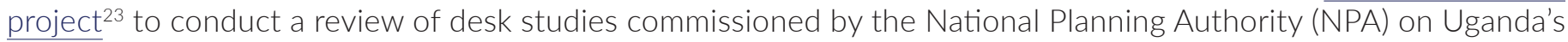
education policies, including the Universal Primary Education policy and national literacy frameworks. Findings were presented to the Government of Uganda (including the NPA, Ministry of Education and Sports and Ministry of Finance) as an external critique of important considerations for shaping and funding the national education agenda under the Third National Development Plan. A project team member is also part of a national literacy technical working group advising the government on successful approaches to improving literacy instruction and teacher training and support.

In India, the British Council's Country Director has offered to promote the findings from a project led by the University of Cambridge on multilingualism and multiliteracy ${ }^{24}$ to India's state governments. The British Council has also proposed to organise a delegation of education ministers from India to visit the UK education authorities, to discuss the project's findings and implications for multilingual education. This has informed the direction of the British Council's policy and practices relating to this topic in its large-scale development work in India and wider South Asia.

Research in Niger, ${ }^{25}$ led by New York University, looked at the impacts of the International Research Committee (IRC)'s socioemotional interventions on students. It found that quality non-formal learning opportunities, such as remedial tutoring programmes, can complement the formal education system in a conflict-affected country like Niger by supporting children's schooling and learning outcomes, with particular benefits of the intervention on socioemotional learning for girls. The project therefore strengthened awareness that teacher training and curricular programmes should consider adding targeted and affordable socio-emotional learning strategies to promote learning and wellbeing in conflictaffected countries. The best practices, research tools and measure were used by the IRC to inform internal research in neighbouring Nigeria.

In South Africa, ${ }^{26}$ research from Stellenbosch University, the University of Cape Town, the University of South Africa and Funda Wande, in collaboration with the Department of Basic Education, contributed to an increased focus at a national level on working towards benchmarks and incremental early learning targets for improvement. Thanks to this and other related research, on 20 June 2019 President Cyril Ramaphosa included reading for meaning in the early grades as one of the five strategic areas for South Africa to focus on in his State of the Nation Address.

The research on teacher effectiveness has also influenced international organisations. For example, the research on teacher effectiveness for children facing multiple disadvantages, including those with disabilities, ${ }^{27}$ led by the University of Cambridge in collaboration with CORD in India and IDEAS in Pakistan, was submitted as written evidence to the International Development Committee (IDC)'s report on DFID's programme Leaving No One Behind in Education, influencing DFID's policy. The research presented as evidence to the Committee was later quoted by the IDC in a letter to Priti Patel (then Secretary of State of DFID) dated 25 April 2017: 'We have heard particularly compelling evidence... including [from] the University of Cambridge to suggest DFID should be spending far more on early childhood education' (IDC 2017). The project also demonstrated how early learning disadvantage starts and proved the need for a Sustainable Development Goals (SDGs) indicator on achieving a minimum proficiency level in reading and mathematics by grade two or three - essential for monitoring children's learning from the early grades of schooling. The UNESCO Institute for Statistics (UIS) described the work as 'pivotal' in the push for monitoring early learning, and so influenced how the education Sustainable Development Goal is measured (Montoya 2018).

Other projects have informed education programmes and plans by international organisations. For example, research in South Africa ${ }^{28}$ led by University College London, in collaboration with JET Education Service and Open University, informed the thinking of the OECD's Strategic Education Governance project, the UNDP's accelerator lab workshop, and the EU working group on school evaluation.

\footnotetext{
${ }^{20}$ The Literacy Laboratory Project (LLP) under the Northern Uganda Literacy Program - ES/M004996/1

${ }^{21}$ Learning outcomes and teacher effectiveness for children facing multiple disadvantages, including those with disabilities: India and Pakistan - ES/M005445/1

${ }_{22}$ Multilingualism and multiliteracy: raising learning outcomes in challenging contexts in primary schools across India - ES/N010345/1

${ }^{23}$ The Literacy Laboratory Project (LLP) under the Northern Uganda Literacy Program - ES/M004996/1

${ }_{24}$ Multilingualism and multiliteracy: raising learning outcomes in challenging contexts in primary schools across India - ES/N010345/1

${ }^{25}$ Promoting children's learning outcomes in conflict-affected countries: evidence for action in Niger - ES/P008607/1

${ }_{26}$ Succeeding against the odds: understanding resilience and exceptionalism in high-functioning township and rural primary schools - ES/N01023X/1

${ }^{27}$ Learning outcomes and teacher effectiveness for children facing multiple disadvantages, including those with disabilities: India and Pakistan - ES/M005445/1

${ }^{28}$ Accountability, capacity, and trust to improve learning outcomes in South Africa: a systems approach - ES/P005888/1
} 


\section{INSTRUMENTAL}

The holy grail of impact is to show how research evidence has influenced the development or amendment of policy, or improved practice or service provision. Sitting above these instrumental level impacts is the aspiration to support developmental impacts and, in the specific case of the RLO, improve learning outcomes. However, demonstrating impact on policy and practice depends on many external factors that are often outside the control of the project/ programme, and therefore attribution or contribution of a specific piece of research to impact is likely to be hard to measure, or may not be possible.

\section{Evidence of having influenced a policy document or statement}

Across the RLO portfolio there are numerous examples of ways in which research evidence has influenced policy decisions across a broad range of decision-making spaces, geographies and learning outcomes

In Honduras, research findings about secondary education from a project ${ }^{29}$ led by the University of California, Berkeley, focusing on examining effective teaching in Honduras, were used by the Ministry of Education to inform policy and practice, particularly relating to including additional curriculum for adolescents and their parents that is intended to reduce rates of early pregnancy and child marriage and their impact on education outcomes. In particular, the project reported that as a result of the meetings with Ministry of Education officials, the government of Honduras decided to expand the Sistema de Aprendizaje Tutorial (Tutorial Learning System or SAT) programme throughout the country as part of its effort to universalise completion of ninth grade, if funding from international donors could be acquired.

Following the Liberian Ministry of Education's announcement in 2016 that it would contract the operation of some government primary schools out to private companies, researchers working with Innovations for Poverty Action examined the effects of these new partnerships and looked at how the schools deliver (or fail to deliver) better outcomes. This research on schools in Liberia has been discussed by the UK's International Development Committee, with the findings on Bridge Academies influencing Lloyd Russell-Moyle MP's correspondence with the Committee. ${ }^{30}$ Following the hearing, the Committee suggested DFID re-consider its working relationship with Bridge Academies, stating that the results of the pilot and the sustainability of Bridge's work in Liberia should be taken into consideration by the Department when assessing its support for Bridge elsewhere. The research team also engaged the Liberian President and her cabinet, including the Minister for Education. Results were also shared with the Ministry of Education and USAID, and various donors and NGOs.

At the national and sub-national level in India, research by a project led by Brunel University focusing on education systems in rural areas ${ }^{31}$ was used by the Government of Chhattisgarh to direct policy, inform supplementary learning materials and guide curriculum revision.

Research by the University of Cambridge and IDEAS in Pakistan ${ }^{32}$ informed the development of a national inclusive education strategy. Findings from the project were described by the Special Secretary of the School Education Department Imran Baloch, as being 'vital in helping to shape and inform Pakistan's new inclusive education policy'.

\section{Shifts in practice - new teaching approaches, including to promote inclusion}

Due to its strong emphasis on building capacity of different groups to engage in research processes and investments in building relationships and networks, many RLO projects were able to report how research had supported instrumental shifts in practice. These changes have not been validated by independent evaluation but do provide an indication of the sustainability of RLO investments in supporting lasting learning outcomes for the populations who have participated in the research.

As highlighted earlier in this report, dissemination of research focused on African Higher Education, led by University College London, UK, together with researchers from the University of Botswana, the University of Cape Coast in Ghana, and Strathmore University in Kenya, has resulted in various shifts in higher education teaching practices. ${ }^{33}$ Participating universities in Kenya, Ghana and Botswana are considering reforms to teaching practice to foster critical thinking. Furthermore, in Kenya the Commission for University Education has incorporated critical thinking into its national work and is supporting universities in adapting their curricula. One private university in Nairobi has adopted critical thinking as a key dimension in its curricular review at an institutional level, while another is incorporating aspects of critical thinking into its staff development programme. In Ghana, public universities involved in the study have embedded critical thinking into their teaching approaches.

In Malawi, the research ${ }^{34}$ led by the University of Birmingham, Sightsavers and the University of Malawi, which looks at promoting greater inclusion of children with disabilities in early childhood development centres in rural areas, has been used by a high-level government steering committee to inform the content and delivery of Early Childhood and Development training to volunteer nursery teachers by including a module on inclusion of children with disabilities.

\footnotetext{
${ }^{29}$ Examining effective teaching in rural Honduran secondary schools - ES/M004864/1

30 Partnership schools for Liberia: impact on accountability mechanisms and education outcomes - ES/P006043/1

${ }^{31}$ Education systems, aspiration and learning in remote rural settings - ES/N01037X/1

${ }^{32}$ Learning outcomes and teacher effectiveness for children facing multiple disadvantages, including those with disabilities: India and Pakistan - ES/M005445/1

${ }_{33}$ Pedagogies for critical thinking: innovation and outcomes in African higher education - ES/M005496/1

${ }^{34}$ Improving curriculum and teaching methods to influence policy and increase the quality of ECDE provision for children with disabilities in Malawi ES/M005453/1
} 


\section{FINDINGS AND IMPLICATIONS}

This paper has explored the broad categories of outcomes that make up the diverse pathways to impact that have been implemented by RLO projects. The mapping exercise, which draws upon project reporting information, provides a unique perspective of pathways to impact at the portfolio level. This highlights the diversity of approaches that researchers use to achieve impact and the important outcomes that are delivered along the way in each of the dimensions of the wheel of impact.

This view of the portfolio highlights the non-linear nature of impact, as well as how projects who delivered strong conceptual or instrumental impacts relied on work to build capacities and relationships. A great deal of investment was made in deepening engagement and sowing the seeds of new concepts and approaches. Many of these seeds bore fruit to deliver positive outcomes for the groups involved in terms of stronger voice and more inclusive decision-making processes, or improved practices and approaches in the classroom.

The RLO has delivered a range of instrumental impacts that have influenced policy decisions in different geographic and learning contexts. Understanding the developmental impacts of those policies on learning outcomes would require policy level evaluations beyond the scope of this analysis. However, it is clear that the insights and evidence generated by the RLO fund will continue to influence thinking and practice around the world well beyond the life of the programme.

This opportunity to look across projects and explore both the breadth and depth of the portfolio allows us to think about how each project's outcomes add up to a rich body of knowledge and dynamic network of researchers, educational professionals and decision makers across multiple levels. It also helps us to explore the synergies across strategies to capture the learning for future researchers and funders, to spark ideas for future conversations around how research supports educational development outcomes.

\section{References}

Clark, L. and Goodier, S. (2019) The Delta of Impact: Mapping a Metaimpact Pathway to Uncover Six Stepping Stones of Research Impact, Working Paper: Expert Analysis from the Impact Initiative, Brighton: Institute of Development Studies and the Impact Initiative

Georgalakis, J. and Rose, P. (eds) (2021) Maximising the Impact of Global Development Research - A New Approach to Knowledge Brokering, Brighton: Institute of Development Studies

Georgalakis, G. and Rose, P. (eds) (2019) 'Exploring Research-Policy Partnerships in International Development' IDS Bulletin 50.1, DOI: 10.19088/1968-2019.100

Georgalakis, J.; Jessani, N.; Oronje, R. and Ramalingam, B. (eds) (2017) The Social Realities of Knowledge for Development, Brighton: Institute of Development Studies and the Impact Initiative

IDC (2017) 'DFID's work on education: Leaving no one behind?', letter to Rt Hon Priti Patel MP, Secretary of State, Department for International Development from Stephen Twigg, MP, Chair of the International Development Committee, House of Commons, April 25

Montoya, S. (2018) We Are Ready to Start Monitoring Early-grade Learning, UNESCO Institute for Statistics blog, 9 November

UKRI ESRC (2021) Impact Toolkit - What is Impact?

UNESCO Institute for Statistics (2017) More Than One-Half of Children and Adolescents Are Not Learning Worldwide, Fact Sheet No. 46, UIS/ FS/2017/ED/46

Wilson-Grau, R. (2018) Outcome Harvesting: Principles, Steps, and Evaluation Applications, Charlotte, NC: Information Age Publishing Zeshan, U. and Webster, J. (eds) (2020) Sign Multilingualism: Sign Language Typology, Vol. 7, Lancaster: Ishara Press and Berlin: de Gruyter.

\section{Credits}

This Working Paper was written by Dr Louise Clark (Monitoring, Evaluation and Learning Manager), Grace Lyn Higdon (Monitoring Evaluation and Learning Specialist) and Stephen Thompson (Research Officer) at the Institute of Development Studies (IDS), and by Elizabeth Tofaris (Communications Specialist) and Pauline Rose (Co-Director of the ESRC-FCDO Impact Initiative) at the Research for Equitable Access and Learning (REAL) Centre, Faculty of Education, University of Cambridge.

The Impact Initiative was funded by the UK's Economic and Social Research Council (ESRC) and the former UK Department for International Development which merged with the Foreign \& Commonwealth Office on 2 September 2020 to become the Foreign, Commonwealth \& Development Office (FCDO). The Impact Initiative seeks to connect policymakers and practitioners with the world-class social science research supported by the ESRC-FCDO Strategic Partnership, maximising the uptake and impact of research from: (i) the Joint Fund for Poverty Alleviation Research, and (ii) the Raising Learning Outcomes in Education Systems Research Programme (RLO). The Impact Initiative seeks to identify synergies between these programmes and their grant holders, support them to exploit influencing and engagement opportunities, and facilitate mutual learning and is a collaboration between the Institute of Development Studies (IDS) and the University of Cambridge's Research for Equitable Access and Learning (REAL) Centre.

The material has been funded by the Economic and Social Research Council and UK aid from the UK Government. However, the views expressed do not necessarily reflect the official policies of the UK Government or ESRC.

This is a product of the Impact Initiative.

(C) Institute of Development Studies, 2021

$\triangle$ info@theimpactinitiative.net

丹 www.theimpactinitiative.net

@The_Impact_Init \#ImpactLessons

All content is available under the Open Government License v.3.0, except where otherwise stated.

ISBN 978-1-78118-789-0

DOI: $\underline{10.35648 / 20.500 .12413 / 11781 / \mathrm{ii} 370}$

THE IMPACT INITIATIVE

For International Development Research 